\title{
Conceptualising women's perinatal well-being: a systematic review of theoretical discussions
}

Franziska Wadephul ${ }^{a}$, Lesley Glover ${ }^{b}$, Julie Jomeen ${ }^{c}$

Health, Nursing and Midwifery; Faculty of Health Sciences; University of Hull

Cottingham Road, Hull, HU6 7RX, United Kingdom

a f.wadephul@hull.ac.uk (corresponding author)

bl.f.glover@hull.ac.uk

cj.jomeen@hull.ac.uk

Conflict of interest: none declared

Ethical approval: not applicable

Funding sources: none

\section{Highlights}

- Perinatal well-being is dynamic, complex and multi-dimensional

- There is a lack of theorising about well-being, particularly in labour and birth

- There is a need for a comprehensive model of perinatal well-being

- Perinatal well-being does not exist in a vacuum but within a wider life context

- Themes identified contribute to a tentative model of perinatal well-being 


\title{
Conceptualising women's perinatal well-being: a systematic review of theoretical discussions
}

\begin{abstract}
Background: Perinatal well-being has increasingly become the focus of research, clinical practice and policy. However, attention has mostly been on a reductionist understanding of well-being based on a mind-body duality. Conceptual clarity around what constitutes well-being beyond this is lacking.

Aim: To systematically review theoretical discussions of perinatal well-being in the academic literature.

Design and methods: A search of online databases identified papers which discussed perinatal wellbeing theoretically, taking a multi-dimensional approach to well-being. Thematic synthesis was used to identify and synthesize relevant elements within the included papers.

Findings: Eight papers were identified for inclusion in this review. All contributed a number of elements towards a theoretical discussion of perinatal well-being. Three themes were developed: (1) the importance of a number of general domains of women's lives and domains specific to the perinatal period, (2) well-being as a subjective and individual experience with physical/embodied, affective, and psychological/cognitive aspects, and (3) the dynamic nature of well-being.

Conclusions and implications for practice: Perinatal well-being is a complex, multi-dimensional construct. Current theoretical discussions in the academic literature do not provide a comprehensive model or conceptualisation covering all aspects of well-being during the perinatal period. Further theoretical work is required, particularly with regards to theorising well-being during labour and birth, the perinatal period as a continuum, and the role played by women's expectations. The themes identified in this review contribute to a tentative model of perinatal well-being, taking note particularly of the dynamic nature of well-being. This model should be refined and validated through empirical work and can then be used to underpin further research and the development of a multidimensional measure of perinatal well-being.
\end{abstract}

\section{Keywords}

Perinatal well-being; maternal well-being; pregnancy; birth; postnatal; systematic review

\section{Introduction}

Over the last two decades there has been an increasing interest in well-being as a focus of policy, practice and research. There is general agreement that well-being takes a more holistic approach and focuses not simply on the absence of illness. In its constitution, the World Health Organisation defines health as 'a state of complete physical, mental and social well-being and not merely the absence of disease or infirmity'. However, the concept of well-being still remains poorly defined and 
frequently appears to be used at a superficial level as 'health and well-being' to cover a wide range of concepts.

The focus on well-being has also been extended to the perinatal period, i.e. pregnancy, labour and the year after birth. However, in the academic literature 'perinatal well-being' is usually used to denote either physical or psychological/emotional well-being rather than taking a truly comprehensive approach. There are numerous examples of research papers which state in the title or abstract that they investigate 'well-being', yet tend to be concerned with physical well-being or perinatal mental health, frequently depression or anxiety. While the holistic nature of well-being has begun to be acknowledged in the perinatal literature, there is still a need to develop a broader understanding of well-being for this particular group. This review will take a multi-dimensional perspective of well-being; this is reflected in the selection of included papers.

Defining and theorising well-being is complex and challenging. There are a wide range of models of general well-being. Diener's (1984) model of subjective well-being consists of three components: positive and negative well-being, and life satisfaction. Ryff (1989) developed a model of psychological well-being with six dimensions which engender positive functioning: self-acceptance, environmental mastery, positive relationships, autonomy, purpose in life, and personal growth. Keyes (1998) added a social dimension to these two models. A more recent approach rooted in positive psychology, Seligman's (2011) PERMA model, includes five components: positive emotions, engagement, relationships, meaning, and accomplishment. Aside from Keyes's addition of a social dimension, these models all take a predominately psychological or quality of life focus. In view of the complex nature of well-being, it seems important to move beyond these areas, towards a more multi-faceted theoretical understanding of well-being, which incorporates physical elements and the wider context of women's lives.

The existence of the wide range of well-being models raises the questions of whether we need a model for the perinatal period. There are a number of characteristics of the perinatal period which justify a conceptualisation of well-being specific to this period. Change is a normal part of human life and should arguably be part of any model of well-being. The perinatal period is a time of transition and change is particularly rapid and profound, not just physically, but also emotionally and in terms of women's sense of identity and purpose. This is most evident during labour and birth, but extends across the perinatal period. Furthermore, this period sees literally the coming-into-existence of a new person and the formation, growth and development of an intimately physical as well as emotional relationship between mother and baby. This close relationship may have a unique impact on the experience of wellbeing during this period. Thirdly, women's perinatal well-being is important not just for their own sake, but also for their babies and families. Supporting women's well-being can therefore have wide-ranging and long-lasting benefits; in order to do this, we need to understand what perinatal well-being is. Finally, applying a well-being perspective to this time in a woman's life, which focuses not just on negative but also on positive changes, may reduce the risk of overpathologising emotional changes in particular (Jomeen \& Martin, 2018). 
Conceptualising perinatal well-being (PWB) is complex and challenging as it is affected by a wide range of factors and changes throughout this period in women's lives (Newham \& Martin, 2013). Nevertheless, in order to operationalise and support perinatal well-being it is important to enhance conceptual clarity and reach agreement between researchers on what we mean by perinatal wellbeing (Ayers \& Olander, 2013; Jomeen \& Martin, 2018). This review paper intends to further our understanding and stimulate discussion about the concept of perinatal well-being. While the focus is on conceptualising PWB itself, this review will also explore factors which do not in themselves constitute PWB, but which affect well-being, as these are often deeply embedded in conceptualisations of PWB.

This paper aims to systematically review theoretical discussions of perinatal well-being, with these specific objectives:

- to identify and critically synthesize theoretical discussions or models of PWB,

- to identify aspects and elements of these conceptualisations of PWB which can contribute towards a comprehensive model of PWB,

- to identify gaps in the formal conceptualisation of PWB,

- to present a tentative model of PWB, and

- to stimulate discussion and identify challenges.

\section{Methods}

\subsection{Search}

The electronic databases Medline, PsycINFO, and CINAHL complete were searched via EBSCOhost using the search terms shown in Table 1 in titles, subject terms, or abstracts. Papers needed to be in English, but no limitations were placed on publication dates; empirical studies of any design as well as discussion papers and editorials were included. The original search took place in March 2018, with a repeat search in February 2019 to identify more recent papers. It was repeated in September 2019 following the development, writing and revision of the review; one further paper was identified.

Table 1 Search terms

\begin{tabular}{ll}
\hline Concept & Search terms \\
\hline $\begin{array}{l}\text { Well-being } \\
\text { Perinatal }\end{array}$ & $\begin{array}{l}\text { wellbeing or well-being or "well being" } \\
\text { maternal or perinatal or prenatal or antenatal or postnatal or antepartum or } \\
\text { postpartum or childbirth or labour or birth } \\
\text { model or models or theory or theories or theoretical or framework or } \\
\text { frameworks or concept or concepts or conceptual }\end{array}$ \\
\hline
\end{tabular}

\subsection{Selection of included papers}


There are a large number of publications about well-being in the perinatal period, of which many relate to either physical or psychological well-being. As it is not feasible to review such a large number of papers, this review includes only papers which explicitly focus on theoretical discussions. The inclusion of terms relating to theory (Table 1 ) reduced the number of identified papers considerably.

In order to be included, papers needed to:

- Provide a theoretical perspective of PWB, by conceptualising or theorising a number of aspects of PWB or PWB as a whole.

- Focus on well-being in the perinatal period, either the whole perinatal period or pregnancy, labour or the postnatal period.

- Take a comprehensive, holistic perspective on well-being, i.e. do not consider only one dimension of well-being such as physical or psychological well-being. Papers needed to include at least two dimensions of well-being.

The following exclusion criteria were applied:

- 'model' referring to statistical models, animal models, treatment models or models of care

- 'framework' referring to reporting or analysis frameworks

- 'theory' referring to theory-based interventions (unless directly relating to wellbeing) or grounded theory

- well-being of mothers of older children or adolescents

- well-being referring solely to infant or child well-being

The search identified 1622 papers (Figure 1). Titles and, if necessary, abstracts were screened in line with the exclusion criteria. The remaining 184 papers were then screened in detail by reading relevant sections in order to ensure they met inclusion criteria. Additional papers were identified through reference list searches. The search and initial screening of papers was carried out by the first author (FW). Selection of papers was discussed with the second author (LG); both were in agreement on which studies to include. The final selection of papers for inclusion was agreed by all authors.

\subsection{Quality assessment}

Due to the diverse nature of the included papers, quality was assessed using a framework developed for this review. For each paper, the framework evaluates (1) the basis for the theoretical discussion (e.g. research literature, empirical work), (2) inclusion of relevant literature, and (3) comprehensiveness and consistency (did the paper cover a wide range of aspects of PWB and was the theoretical discussion of PWB and its elements consistent) (see Supplementary file 1). As the papers were so diverse in nature, the quality assessment did not assign a score or quality label to each paper, but was used to evaluate the overall contribution to the theoretical discussion of PWB, which in turn informed the synthesis. The first author (FW) carried out quality assessments for all 
included papers. The second author (LG) assessed four papers for quality; there was broad agreement on quality between the first and second author. Where there was disagreement, the issues were discussed to reach agreement. The assessments in Supplementary file 1 are jointly agreed.

Figure 1 PRISMA flow diagram (Moher, Liberati, Tetzlaff, \& Altman, 2009)

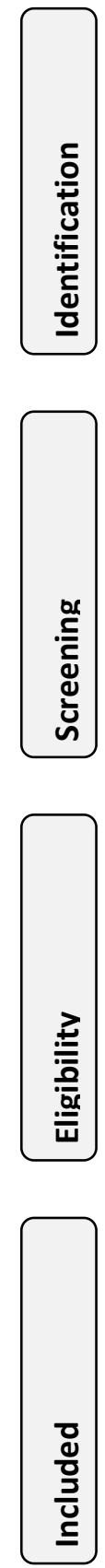

Records identified through database searching $(n=2423)$

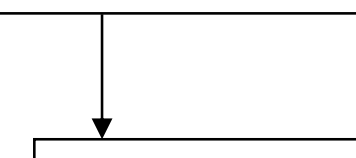

Records after duplicates removed $(n=1622)$
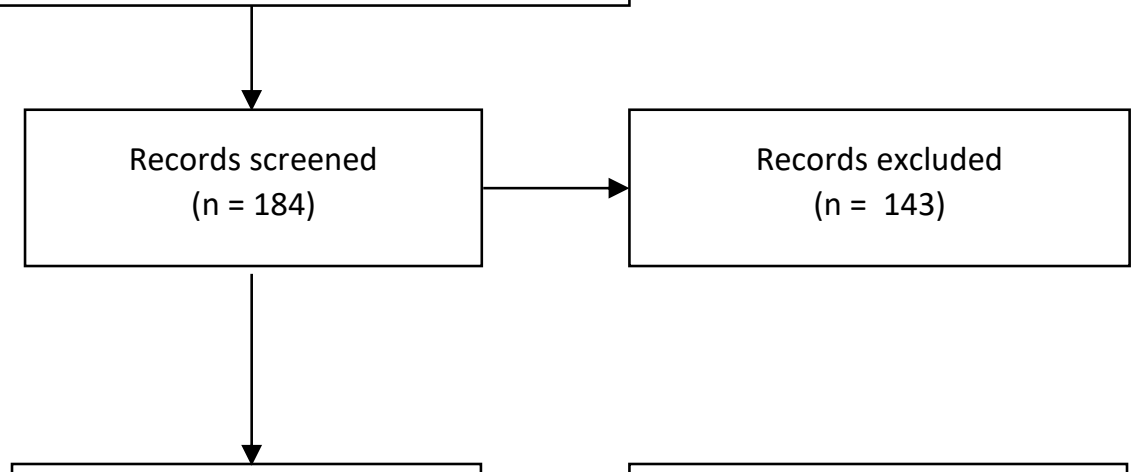

Full-text articles assessed for eligibility

( $n=41)$

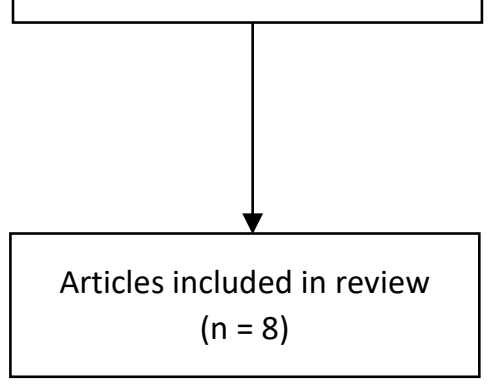

Full-text articles excluded, with reasons

$(n=33)$

Not specifically perinatal Approach to wellbeing not comprehensive enough $\quad 17$ Not sufficiently theoretical Conference abstract only
5
17
9
2 other sources $(n=11)$ 
Table 2 Conceptualising perinatal well-being: included papers

\begin{tabular}{|c|c|c|c|c|}
\hline Paper & Aim & Theoretical discussion/model & Conceptualisation of PWB & $\begin{array}{l}\text { Perinatal } \\
\text { period }\end{array}$ \\
\hline $\begin{array}{c}\text { Alderdice et } \\
\text { al. (2017) }\end{array}$ & $\begin{array}{l}\text { To describe the } \\
\text { psychometric } \\
\text { properties of the } \\
\text { Well-being in } \\
\text { Pregnancy } \\
\text { questionnaire }\end{array}$ & $\begin{array}{l}\text { Measure: Well-being in } \\
\text { Pregnancy questionnaire } \\
\text { Based on focus-groups and } \\
\text { research (studies of women's } \\
\text { experiences), tested on five } \\
\text { pregnant women; validated } \\
\text { with } 318 \text { women }\end{array}$ & $\begin{array}{l}\text { Multifaceted, encompasses positive and negative emotions and satisfaction with } \\
\text { life; cognitive and affective components; domain satisfaction and life } \\
\text { satisfaction } \\
\text { Measure: } 12 \text { pregnancy-specific questions; two factors: 1) positive experiences } \\
\text { of pregnancy (positive affect and satisfaction scale), 2) concerns about health } \\
\text { and pregnancy outcomes (concerns scale) }\end{array}$ & Pregnancy \\
\hline $\begin{array}{l}\text { Allan et al. } \\
(2013)\end{array}$ & $\begin{array}{l}\text { To conceptualise } \\
\text { perinatal well-being } \\
\text { and review the } \\
\text { relevant literature }\end{array}$ & $\begin{array}{l}\text { Concept analysis of perinatal } \\
\text { well-being } \\
\text { Based on papers about } \\
\text { emotional and psychological } \\
\text { well-being in women (not just } \\
\text { perinatal) }\end{array}$ & $\begin{array}{l}\text { Dynamic, complex, multiple inter-related facets; 'the cognitive and/or affective } \\
\text { self-evaluation of the individual's life specific to the period before and/or after } \\
\text { childbirth, which encompasses a multitude of elements such as: physical, } \\
\text { psychological, social, spiritual, economic and ecological' (p. 390) }\end{array}$ & Perinatal \\
\hline $\begin{array}{c}\text { Clarry \& } \\
\text { Carson } \\
(2018)\end{array}$ & $\begin{array}{l}\text { To develop a positive } \\
\text { measure of maternal } \\
\text { well-being }\end{array}$ & $\begin{array}{l}\text { Clarry Maternal Emotional } \\
\text { Wellbeing Scale (C-MEWS) } \\
\text { Literature review of external } \\
\text { factors and interventions; } \\
\text { items specifically developed as } \\
\text { well as 'borrowed' from a } \\
\text { number of positive psychology } \\
\text { scales; postnatal women / } \\
\text { pilot study in choice of items }\end{array}$ & $\begin{array}{l}\text { 'wellbeing refers specifically to the psychological wellbeing of mothers, } \\
\text { represented by the presence of contributing factors such as feeling of purpose } \\
\text { and reward, a love and bond with their child, maintaining the ability to uphold } \\
\text { social and familial relationships and a confidence in decision making with a } \\
\text { feeling of positivity toward their lifestyle and responsibilities.' (p. 399); defined } \\
\text { as an 'individual mechanism' } \\
\text { Measure: } 30 \text {-item scale with eight categories: negative emotion, positive } \\
\text { purpose and reward perception, social connection, decision making and } \\
\text { responsibilities, lifestyle, positive emotion, bond and love for baby, strength of } \\
\text { opinion }\end{array}$ & $\begin{array}{l}\text { Postnatal/ } \\
\text { maternal }\end{array}$ \\
\hline $\begin{array}{l}\text { Fahey \& } \\
\text { Shenassa } \\
(2013)\end{array}$ & $\begin{array}{l}\text { To provide a health } \\
\text { promotion approach } \\
\text { to meeting the needs } \\
\text { of postnatal women }\end{array}$ & $\begin{array}{l}\text { Perinatal Maternal Health } \\
\text { Promotion Model } \\
\text { Based on a health promotion } \\
\text { approach }\end{array}$ & $\begin{array}{l}\text { Multidimensional, extends beyond absence of medical problems. A healthy } \\
\text { postnatal period includes 'not only physical recovery but also the ability to meet } \\
\text { individual needs and successfully transition into motherhood' (p. 613). Well- } \\
\text { being depends on skills which promote well-being and available external } \\
\text { resources. } \\
\text { Model: Core elements (physical recovery; care of self, infant and family; } \\
\text { maternal role elements), individual health enhancing skills (mobilisation of } \\
\text { social support; self-efficacy; positive coping; realistic expectations), external }\end{array}$ & Postnatal \\
\hline
\end{tabular}




\begin{tabular}{|c|c|c|c|c|}
\hline & & & $\begin{array}{l}\text { resources (access to clinical services, social and other support services, } \\
\text { information, material resources) }\end{array}$ & \\
\hline $\begin{array}{l}\text { Jomeen \& } \\
\text { Martin } \\
(2018)\end{array}$ & $\begin{array}{l}\text { Discussion paper on } \\
\text { perinatal well-being } \\
\text { and quality of life }\end{array}$ & $\begin{array}{l}\text { Discussion of conceptualisation } \\
\text { and assessment of perinatal } \\
\text { well-being }\end{array}$ & $\begin{array}{l}\text { Well-being as a 'multi-faceted and evolving continuum ranging from a positive to } \\
\text { a negative sense of well-being' (p. 215), based on individual perception and } \\
\text { self-evaluation. Components of well-being are 'inherently implicated and } \\
\text { rooted in the intrinsic abilities of women themselves' and the 'fluidity of the } \\
\text { construct across a puerperium that is distinctively dynamic for women' (p. 215) }\end{array}$ & Perinatal \\
\hline $\begin{array}{l}\text { O’Brien et al. } \\
(1999)\end{array}$ & $\begin{array}{l}\text { Editorial on perinatal } \\
\text { comfort and well- } \\
\text { being }\end{array}$ & $\begin{array}{l}\text { Perinatal Comfort and Well- } \\
\text { Being }\end{array}$ & $\begin{array}{l}\text { 'Comfort and well-being is a multidimensional concept that relates both to the } \\
\text { strength of perinatal women (and their families) and to how they are perceived } \\
\text { by their communities.' (p. 288) }\end{array}$ & Perinatal \\
\hline $\begin{array}{l}\text { Reis \& } \\
\text { Alligood } \\
(2008)\end{array}$ & $\begin{array}{l}\text { To report findings from } \\
\text { a pilot study } \\
\text { appraising well-being } \\
\text { in pregnancy }\end{array}$ & $\begin{array}{l}\text { Based on Science of Unitary } \\
\text { Human Beings }\end{array}$ & $\begin{array}{l}\text { 'Well-being in pregnancy embodies wholeness and evolutionary change within } \\
\text { the human and environmental energy field through the process of dynamic } \\
\text { patterning of both the mother and child individual and group energy field.' (p. } \\
\text { 9); pregnancy viewed from a positive perspective rather than as a medical } \\
\text { problem }\end{array}$ & Pregnancy \\
\hline $\begin{array}{l}\text { Symon et al. } \\
(2002)\end{array}$ & $\begin{array}{l}\text { To test the validity of } \\
\text { the Mother- } \\
\text { Generated Index }\end{array}$ & $\begin{array}{l}\text { Mother-Generated Index } \\
\text { (postnatal quality of life) } \\
\text { Based on the Patient-Generated } \\
\text { Index }{ }^{1} \text {; tested and validated in } \\
\text { a pilot study }\end{array}$ & $\begin{array}{l}\text { Encompassing a wide range of areas of life, emphasis on subjectivity and } \\
\text { individual experience of PWB. Assesses quality of life, but well-being is included } \\
\text { in discussion; factors contributing to well-being are specified by women } \\
\text { themselves; described as a 'fairly reliable indicator of well-being' (p. 45) } \\
\text { Three-step questionnaire: 1) mother specifies maximum of eight areas of life } \\
\text { which have been affected by having had a baby (and if negatively/positively); 2) } \\
\text { gives each area a score out of } 10 \text { depending on how she has felt about it; 3) } \\
\text { allocates } 20 \text { points between areas according to importance }\end{array}$ & Postnatal $^{2}$ \\
\hline
\end{tabular}

${ }^{1}$ Ruta, D.A., Garratt, A.M., Leng, M. et al (1994). A new approach to the measurement of quality of life: the patient generated index (PGI). Medical Care 32:1109-1126.

2 Has subsequently been applied to pregnancy. 


\subsection{Synthesis}

The included papers were not uniform in nature. While some were empirical, using a quantitative approach, others solely provided theoretical discussions. The focus of this review is on the theoretical rather than the empirical, with the aim to synthesize the core elements of conceptualisations of PWB. An approach to data abstraction appropriate to a review of empirical studies was therefore not suitable for this review. Instead, a qualitative approach to evidence synthesis was chosen. Thomas and Harden (2008) propose three stages for a thematic synthesis: coding text, developing descriptive themes, and generating analytical themes. We broadly followed these stages, but made some adaptations appropriate to this review. (1) As the focus of this review is on theoretical discussions of PWB, texts were not coded line-by-line, as suggested by Thomas and Harden (2008), but only when relevant concepts were discussed. These concepts were highlighted in the text and then transferred to the first column of a table (see supplementary material). (2) A descriptive theme for each original concept was then added in the second column of the table. Some concepts contained more than one descriptive theme. These themes provided a more abstract description of the original concepts. (3) Descriptive themes from all papers were compared and grouped into even more abstract and analytical themes. These were further removed from the original papers and enabled a synthesis of concepts which went beyond that of individual papers. Steps (1) and (2) of this process were carried out by the first author (FW), with feedback from the other authors. In step (3), descriptive themes were developed by FW and then agreed between all three authors.

\section{Results}

\subsection{Description of the theoretical discussions}

This review identified 8 papers providing theoretical discussions of perinatal well-being (Table 2). Three of the included papers describe the development of measures while the other four describe models or concepts of perinatal well-being. In their concept analysis, Allan, Carrick-Sen, and Martin (2013) described perinatal well-being as a complex, dynamic concept which is based on women's perceptions and self-evaluations. The health promotion model developed by Fahey and Shenassa (2013) focuses on the development of skills which promote well-being in the perinatal period. Jomeen and Martin (2018) discuss conceptualisations and measurement of perinatal well-being and compare it to the concept of quality of life. In an editorial, O'Brien and colleagues (1999) discuss comfort and well-being in the perinatal period. Reis and Alligood (2008) applied Rogers' Science of Unitary Human Beings to pregnancy, taking a more holistic approach to health than a purely biological perspective and emphasizing the importance of optimism.

Alderdice and colleagues (2017) developed and tested a measure of well-being in pregnancy, the Well-being in Pregnancy (WiP) questionnaire, based on focus groups and findings from the literature. Items go beyond the purely physical experience by including attitudes, psychological aspects, bonding with the baby, concerns about relationships and support from health professionals. The Clarry Maternal Emotional Wellbeing Scale (C-MEWS) (Clarry \& Carson, 2018) aims to provide a 
positive measure of maternal well-being, with a focus on emotional well-being, but also including other domains. The Mother-Generated Index (Symon, MacDonald, \& Ruta, 2002) allows women to specify areas of their life which have been affected by becoming a parent, rather than providing a pre-defined list; while it measures quality of life, it is also described as an indicator of well-being.

The following sections synthesize pertinent theoretical elements of well-being from the included papers into three themes. These relate to (1) the domains of women's lives which are involved in well-being, (2) the experience of well-being, and (3) time and change. While the identified themes, and their sub-themes, are distinct, they are closely interrelated.

\subsection{Domains of women's lives involved in well-being}

The included papers describe PWB as 'multidimensional', 'multifaceted' or 'multifactorial'. Some propose a number of broad dimensions, such as physical, psychological, social, spiritual, economic, ecological (Allan et al., 2013); physiological, spiritual, emotional, social (O'Brien et al., 1999); and environmental, physical and social (Clarry \& Carson, 2018). Others do not elaborate on dimensions beyond stating that well-being does not relate exclusively to physical or mental health (Clarry \& Carson, 2018; Fahey \& Shenassa, 2013; Jomeen \& Martin, 2018; Reis \& Alligood, 2008, 2014). The Mother-Generated Index (Symon et al., 2002) takes a different approach by asking women to list the areas of their lives which have been affected by becoming a parent, thereby acknowledging the wide-reaching and subjective nature of well-being; women identified a range of domains, including physical, social, psychological, economic, mental, emotional, sexual and spiritual domains.

All papers acknowledge, to varying degrees, that a number of domains or dimensions of women's lives have an impact on women's well-being and are in turn affected by well-being. However, there are also issues specific to the perinatal period which have great significance for women's well-being. Most of the included papers specifically refer to these and for some it is the main focus (Alderdice et al., 2017; Clarry \& Carson, 2018; Fahey \& Shenassa, 2013). These issues specific to the perinatal period include, but are not limited to: the relationship with the fetus or baby; changes in relationships with the partner; other children and other family members; caring responsibilities; changes to employment status; the physical impact of pregnancy and birth; breastfeeding; sociocultural attitudes to pregnancy and motherhood; maternal role attainment; and perinatal mental health problems.

It is clear from the included papers that the social dimension in particular is very significant for perinatal well-being, including the wider socio-cultural context as well as a range of relationships and support networks. The role of women's community in PWB, in particular communities' perceptions, values and responses, is highlighted by O'Brien et al. (1999). Wider societal views also impact on PWB (Allan et al., 2013; O'Brien et al., 1999). Partner and family relationships play an important role. Included papers discussed concerns and problems with respect to family relationships (Alderdice et al., 2017; Allan et al., 2013; Symon et al., 2002), changing relationships (Clarry \& Carson, 2018; Symon et al., 2002), satisfaction with relationships (Clarry \& Carson, 2018), family functioning (Jomeen \& Martin, 2018), and the significance of families for women's experiences of PWB (O'Brien et al., 1999). The importance of the mother-baby relationship in PWB 
was highlighted by several papers, particularly bonding with the baby and feelings towards the baby (Alderdice et al., 2017; Clarry \& Carson, 2018; Fahey \& Shenassa, 2013; Jomeen \& Martin, 2018; O'Brien et al., 1999; Symon et al., 2002) and caring responsibilities for the baby (Clarry \& Carson, 2018; Fahey \& Shenassa, 2013). Reis and Alligood (2008) and O'Brien et al. (1999) highlight the integral dyadic relationship between mother and fetus/baby and O'Brien et al. (1999) specifically acknowledge how this relationship changes over time.

The relationship with health professionals, women's access to clinical services and information, and women's experiences of health care are discussed by two papers (Alderdice et al., 2017; Fahey \& Shenassa, 2013). Support from others and support networks also affect women's PWB (Allan et al., 2013; Clarry \& Carson, 2018; Fahey \& Shenassa, 2013; Reis \& Alligood, 2008). Fahey and Shenassa (2013) in particular discuss women's needs for, and expectations of, emotional, instrumental and information support, including barriers to help-seeking and the role of support in coping with changes.

\subsection{The experience of well-being}

\subsubsection{Well-being as a subjective, individual experience}

While there are commonalities in women's perinatal experiences, there are also important differences due to personal and contextual factors. Consequently, well-being is an individual and subjective experience. O'Brien et al. (1999, p. 290), for example, refer to the 'primacy of women's experiences' and Allan et al. (2013) focus on the importance of women's self-evaluation, stating that how women evaluate their lives cognitively and/or affectively determines their state of perinatal well-being. The included measures (Alderdice et al., 2017; Clarry \& Carson, 2018; Symon et al., 2002) are based on individual women's subjective evaluations of their well-being. The Mother-Generated Index (Symon et al., 2002) takes the focus on individual experience furthest by asking women to identify aspects of their life affected by motherhood, rather than scoring their experiences on predefined items. Jomeen and Martin (2018) emphasize how women's perceptions of well-being are mediated by biological, social and psychological factors.

\subsubsection{Physical/embodied experience}

The included papers discuss the physical experience of well-being to varying degrees. The WiP questionnaire (Alderdice et al., 2017) contains items relating to women's concerns about their own health and the emotional impact of physical symptoms of pregnancy. Allan et al. (2013) include a physical domain in their conceptualisation of PWB. Clarry and Carson (2018) discuss physical health in their paper, but do not include it in the measure they develop. The Mother-Generated Index (Symon et al., 2002) gives women the option to include aspects of physical health. The health promotion model developed by Fahey and Shenassa (2013) explicitly includes physical recovery as a core element, while physical experiences of well-being appear to be implicitly included by O'Brien et al. (1999) and Reis and Alligood (2008). In the majority of papers women's physical experiences relate to physical concerns and ill-health and recovery from pregnancy and birth. Alderdice et al. (2017) and Allan et al. (2013) also refer to the impact of pregnancy on women's body image and satisfaction. 


\subsubsection{Affective experience}

Several of the included papers describe perinatal well-being as having an affective component. The WiP questionnaire (Alderdice et al., 2017) identified two relatively independent factors relating to positive affect and negative affect or concerns, suggesting that both need to be assessed to obtain a full measure of well-being. Allan et al. (2013) and Clarry and Carson (2018) also identify negative and positive emotions as important components of well-being. Explicitly identified positive emotions include positive feelings about the pregnancy (Alderdice et al., 2017), happiness (Allan et al., 2013; Clarry \& Carson, 2018; Jomeen \& Martin, 2018; Symon et al., 2002), feeling calm (Clarry \& Carson, 2018), feeling loved (Clarry \& Carson, 2018), and experiencing pleasure from interaction with the baby (Jomeen \& Martin, 2018; Symon et al., 2002). Negative emotions include anxiety, worry and concerns (generally and about changing relationships, birth and the baby's and woman's own health) (Alderdice et al., 2017; Clarry \& Carson, 2018), feeling tense, overwhelmed and down (Clarry \& Carson, 2018), and negative feelings towards the baby (Symon et al., 2002). Emotional aspects of well-being do not occur in a vacuum, but can, for example, be linked to physical status (Jomeen \& Martin, 2018).

\subsubsection{Psychological/cognitive experience}

The included papers identified a wide range of psychological/cognitive aspects of perinatal wellbeing (Table 3). One important component of well-being may be individuals' ability to cope with challenges. Fahey and Shenassa (2013) in particular discuss coping with challenges and women's use of individual coping skills and external resources.

[Table 3 here]

\subsubsection{Balance: positive and negative experiences}

Physical, affective and psychological/cognitive experiences of well-being, and women's evaluations of these experiences, can be negative and positive. Several papers highlighted that while discussions of PWB often focus on ill-health and negative experiences (Allan et al., 2013; Clarry \& Carson, 2018), conceptualisation of PWB should also include positive experiences and evaluation (Alderdice et al., 2017; Allan et al., 2013; Clarry \& Carson, 2018, Jomeen \& Martin, 2018). Symon et al. (2002), for example, found that women listed both negative and positive experiences when completing the MGI. Jomeen and Martin (2018) emphasize the importance of positive capabilities and emotions, as well as a positive evaluation of life.

\subsection{Time and change}

The papers included in this review cover different parts of the perinatal period: the whole perinatal period (Allan et al., 2013; O'Brien et al., 1999), pregnancy (Alderdice et al., 2017; Reis \& Alligood, 2008) or the postnatal period (Clarry \& Carson, 2018; Fahey \& Shenassa, 2013; Symon et al., 2002). It is notable that none of the papers specifically refer to well-being during labour and birth. 
The perinatal period is a time of transition which brings with it not only physical and emotional changes, but also changes in relationships, responsibilities, priorities, needs and identity (Allan et al., 2013; Fahey \& Shenassa, 2013; Jomeen \& Martin, 2018; O'Brien et al., 1999; Reis \& Alligood, 2008). It therefore follows that perinatal well-being is dynamic and changeable and is likely to change throughout pregnancy and the postnatal period. The dynamic nature of PWB, involving fluctuations of well-being over time, is explicitly acknowledged by several of the papers (Allan et al., 2013; Jomeen \& Martin, 2018; O'Brien et al., 1999; Reis \& Alligood, 2008). How women adjust to the changes brought about by the transition to parenthood is crucial for their well-being (Jomeen \& Martin, 2018).

\section{Discussion}

This review identified a wide range of theoretical discussions of perinatal well-being which varied in approach, purpose and complexity. While none provide a truly comprehensive model of perinatal well-being, all contributed some elements towards a model and can enhance our understanding of perinatal well-being. The focus of this review is on theoretical elements of PWB, rather than what specifically enhances or reduces well-being. On the whole, the papers did not comment about which domains are more integral to well-being, with the exception of the social dimension and relationships, which appear to be particularly significant.

\subsection{Domains: general and specific}

The papers included in this review discussed a wide range of domains of women's lives which affect PWB, both general and specific to the perinatal period. It is reasonable to assume that women's well-being in the perinatal period is potentially affected by all areas of their lives, though the impact of any one area varies between women, and over time for individual women.

This is reflected in growing acknowledgement over the last few decades of the impact of socioeconomic, cultural factors and environmental impact on well-being which goes beyond a purely medical model. For example, women affected by complex social factors are more likely to book later for antenatal care, which is associated with poorer pregnancy outcomes (CEMACH, 2007; Knight et al., 2018). Women who lack sufficient economic resources are more likely to develop postnatal depression and less likely to seek treatment (Abrams \& Curran, 2009; Segre, O'Hara, Arndt, \& Stuart, 2007). Cultural factors are also relevant; while postnatal depression appears to occur in different cultures, cultural norms, expectations and beliefs about it and how it is experienced by women may differ between cultures (Oates et al., 2018; Posmontier \& Horowitz, 2004; Sampson, Torres, Duron, $\&$ Davidson, 2018). Research suggests that wider socio-cultural discourses around motherhood have a profound influence on women's experiences of the perinatal period (Choi, Henshaw, Baker, \& Tree, 2005; Sampson et al., 2018; Wall, 2013). The included papers highlighted the importance of relationships to well-being, including women's relationships with the baby, their partner, older children, other family members, friends, and health professionals. The quality of relationships can have a positive as well as negative impact on women's experiences of well-being (Alderdice \& 
Gargan, 2019; Kirova \& Snell, 2019). Appropriate support, both formal and informal, has the potential to enhance women's well-being during the perinatal period (McLeish \& Redshaw, 2017).

The papers included in this review also identified a range of issues which are specific to the perinatal period. There is a wealth of evidence exploring how the factors specific to the perinatal period affect well-being. For example, infant behavioural patterns considered 'difficult', such as crying and sleep problems, are associated with poor maternal health (Russell \& Lincoln, 2016; Smart \& Hiscock, 2007). Issues specific to the perinatal period are clearly very pertinent at this time and can exert a considerable influence on well-being. Women's experiences of pregnancy and motherhood, and their well-being during this period, cannot be considered in isolation from the wider context of their lives, but it is also important to acknowledge that during the perinatal period women's experiences and well-being are affected by issues which are very specific to this period.

\subsection{Experiences of well-being}

It is important that a conceptualisation of PWB reflects subjective experiences and differences between women (Jomeen \& Martin, 2018). The included papers describe well-being as subjective, based on diverse individual experiences. This is reflected in research; a review of research exploring women's experiences of labour and birth (Larkin, Begley, \& Devane, 2009), for example, emphasised women's unique, individual experiences of labour, and there is a wide variation in the experience of subjective well-being in parenthood (Galatzer-Levy, Mazursky, Mancini, \& Bonanno, 2011).

The individualised, subjective nature of PWB means that measurement of is difficult. The focus of the MGI on women's individualised experiences, for instance, makes it difficult to generalise from findings and has implications for the reliability and validity of the measure. A further potential problem is that the subjective nature of PWB may lead to claims that women's levels of well-being are solely due to their subjective evaluations. Allan et al. (2013), for example, suggest that women's well-being is determined by the outcome of their self-evaluation and Clarry and Carson (2018) describe well-being as an individual mechanism. It may be possible to conclude from this that women themselves are solely responsible for their well-being and that it is always within their power to increase their well-being. This perspective neglects the significant influences of the wider context and conditions of women's lives. While experiences of well-being are clearly individual and subjective, they do not occur in a vacuum and are affected by a wide range of contextual factors.

The perinatal period is accompanied by a range of physical changes which have the potential to enhance or negatively impact well-being. Postnatal physical discomfort is, for example, associated with increased risk of postnatal depression (Schaffir et al., 2018). Women may also find that physical changes in the perinatal period change how they experience and perceive their body, which may affect well-being (Hodgkinson, Smith, \& Wittkowski, 2014; Neiterman \& Fox, 2017) and some women have very positive embodied experiences during labour (Parratt, 2010). Affective experiences of well-being were prominent in the majority of papers included in the review. The inclusion of positive and negative affect reflects theoretical discussions in the well-being literature (e.g. Diener, 1994). There is now a large body of research literature which explores women's emotional experiences during the perinatal period. 
Many of the psychological and cognitive experiences identified in the included papers reflect the six dimensions in Ryff's model of psychological well-being: autonomy, environmental mastery, personal growth, positive relationships, purpose in life and self-acceptance (Ryff \& Keyes, 1995). These cognitive components of well-being are likely to have a considerable effect on well-being, but are often not included in assessments or conceptualisations of well-being. Research in this area has increased over recent decades. There is, for example, evidence of changes in self-concept (Darvill, Skirton, \& Farrand, 2010), confidence (Kristensen, Simonsen, Trillingsgaard, Pontoppidan, \& Kronborg, 2018), and self-efficacy (Law et al., 2018) during the transition to motherhood and postnatally. The ability to adapt and cope with change is also relevant in this context. Fahey and Shenassa (2013), for example, include positive coping strategies in their Perinatal Maternal Health Promotion Model. This conceptualises well-being as a positive construct which focuses on capabilities and resources, rather than a negative construct emphasising deficiencies (Greco, Skordis-Worrall, Mkandawire, \& Mills, 2015; Jomeen \& Martin, 2018; Sen, 1993).

Findings from this review have highlighted how experiences of well-being can be affected positively and negatively. This contrasts with dichotomous depictions of the perinatal period as either exclusively a time of joy and happiness, as often portrayed in the media, or as a time of challenge when women struggle to cope with the demands of motherhood and mental health issues. It is important to acknowledge that women's experiences are likely to be both positive and negative and that individuals may have relatively high levels of well-being despite considerable difficulties in one or more aspects of their lives, linking to coping strategies and capabilities discussed above. Women's well-being in the perinatal period can therefore be conceptualised in terms of balance, reflecting the approach taken by Dodge, Daly, Huyton, and Sanders (2012) who propose an equilibrium definition of well-being as the balance between challenges and an individual's available resources.

\subsection{The dimension of time}

While pregnancy, labour/birth and the postnatal period are distinct segments of time, they are interrelated and present a continuum. There are, for example, clear links between well-being during pregnancy and the postnatal period, for example between antenatal and postnatal mental health problems (Milgrom et al., 2008; Verreault et al., 2014). None of the included papers specifically discuss well-being in labour and birth. This is surprising, considering that childbirth is an integral part of the perinatal period and the body of evidence which suggests that women's labour and birth experiences can have a considerable impact on postnatal experiences and well-being (Bell \& Andersson, 2016; Byrne, Egan, Mac Neela, \& Sarma, 2017; Larkin et al., 2009; McKenzie-McHarg et al., 2015). Conversely, feelings and thoughts about childbirth also impact on women's experience of pregnancy and may lead to varying levels of anxiety (Nilsson et al., 2018). However, women's wellbeing during childbirth is an important issue in itself; while there has been research in this area (Crowther, Stephen, \& Hall, 2019; Downe, Finlayson, Oladapo, Bonet, \& Gülmezoglu, 2018; Larkin et al., 2009; Lundgren, 2005; Simkin, 1991), there appears to be a lack of conceptual work. Crowther (2017) proposed a holistic model of the experience of childbirth, the ecological of childbirth model, comprising six dimensions: spatial, context, embodied, relationality, temporality, and mystery. While 
this model does not directly focus on well-being, using it as a lens through which to explore wellbeing during labour and birth may enhance our understanding of well-being during this time.

Well-being fluctuates not just throughout the perinatal period, but also over shorter periods of time, including daily (Newham \& Martin, 2013). While some of the conceptual discussions included in this review acknowledged the dynamic nature of perinatal well-being (Allan et al., 2013; Jomeen \& Martin, 2018; O'Brien et al., 1999), none offer a satisfactory way of incorporating them into a model.

\subsection{What is missing?}

Several elements which are missing from the theoretical discussions have already been identified. Currently, there appears to be little theorising around well-being during labour and birth, despite its importance for postnatal well-being. While some of the included papers have included discussion of changes over time in well-being, there are other temporal aspects which may need further attention, including the conceptualisation of the perinatal period as a continuum and the inclusion of a life-course perspective which extends the temporal dimension of women's well-being beyond the perinatal period (Pies, Parthasarathy, \& Posner, 2012). Another issue not discussed in detail by any of the included papers is the relevance of women's environment and space for well-being. While this could be part of a wider environmental domain, it may warrant more explicit discussion, particularly in terms of the importance of environment during labour and birth (Fahy \& Parratt, 2006) and the early postnatal period when women may be limited in their ability to travel and move beyond their own domestic space. Finally, women's expectations of the perinatal period, and how these match up to reality, are of great significance for well-being, as suggested by research evidence (e.g. Hauck, Fenwick, Downie, \& Butt, 2007; Tammentie, Paavilainen, Åstedt-Kurki, \& Tarkka, 2004). Fahey and Shenassa (2013) briefly discuss this, but overall there is a lack of theoretical discussion of expectations and reality in the literature.

\subsection{A tentative model of perinatal well-being}

Based on the theoretical elements of PWB in the papers included in this review, we propose a tentative model of PWB (Figure 2). The three outer concentric circles represent the context of women's lives with, from the inside to the outside, increasing distance to the individual woman, reflecting Bronfenbrenner's ecological systems theory (Bronfenbrenner, 2005). The outer circle relates to the wider socio-economic and culture context, which affects the construct of well-being as well as women's experiences of well-being. The 'community' circles refers to the wider community in which women live, both physically (e.g. a town or neighbourhood) and virtually (e.g. various group identities). 'Immediate environment' includes family units, extended families, friendship groups, and possibly work environments. What constitutes the 'community' and 'immediate environment' varies between women, reflecting their circumstances. The fourth concentric circle includes individual characteristics which do not in themselves constitute well-being. The inner circle is the core of wellbeing, relating to perceptions and experiences of well-being, and consist of interrelated affective, psychological/cognitive and physical experiences. 
This model demonstrates the importance of being aware of the wider context of well-being and on holistic nature of women's experience of well-being, which extends across affective, psychological and physical aspects. Experiences of PWB do not occur in a vacuum, but exist within a complex, multi-faceted environment. Empirical work is needed to evaluate and refine this model.

\section{Figure 2 A tentative model of perinatal well-being}

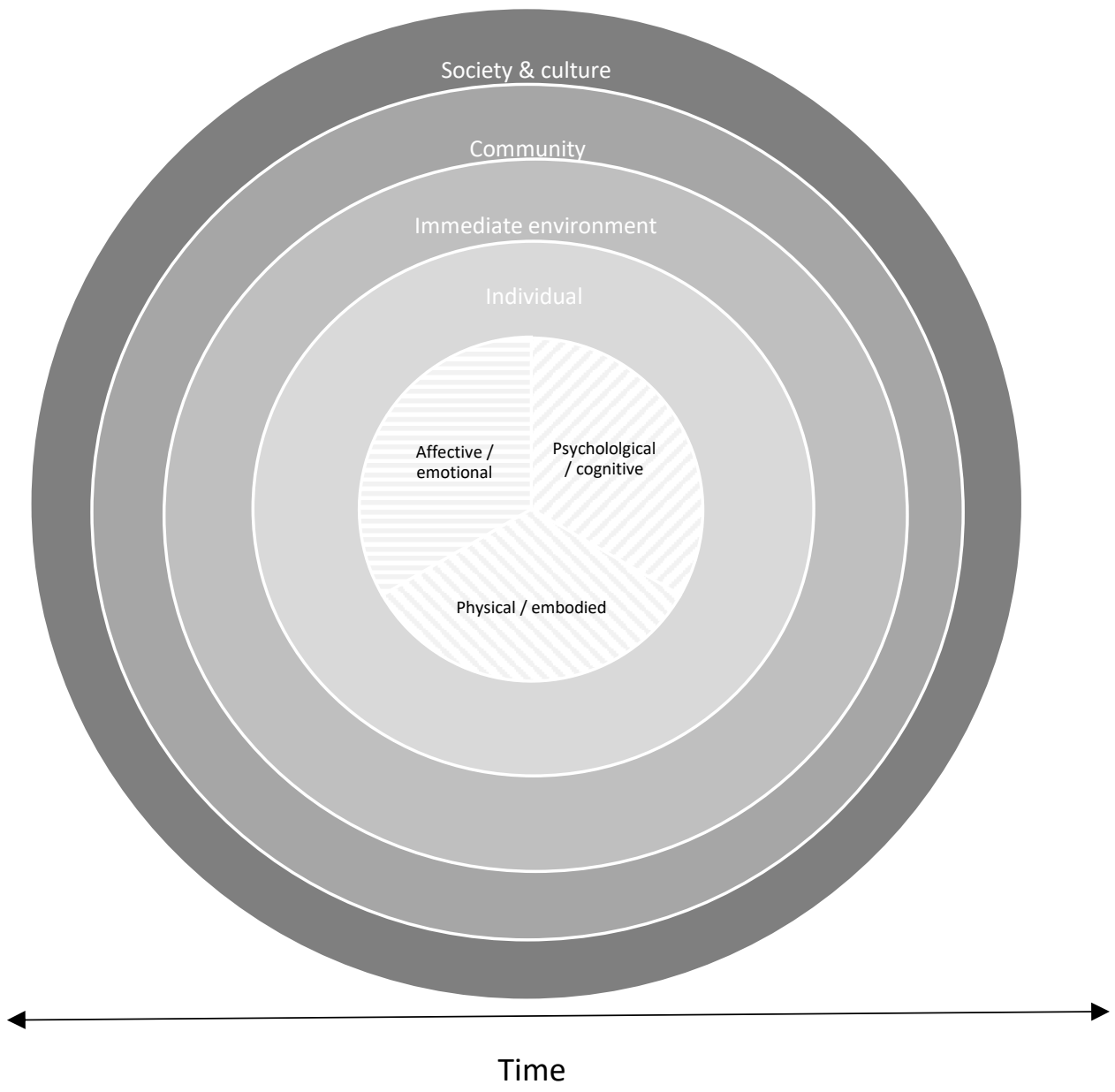

\subsection{Implications}

This review provides an overview and synthesis of theoretical discussions and conceptualisations of PWB. The resulting tentative model can be used to inform future research and underpin the development of a measure of PWB. Further research is required to refine and validate the model. In clinical practice, the review supports an approach which takes into account the wider context of women's lives, rather than considering their well-being in a vacuum. The review underlines the multi-faceted nature of well-being and the importance of a holistic approach in assessing PWB and supporting women throughout the perinatal period. 


\subsection{Strengths and limitations}

This is the first review which systematically brings together theoretical discussions of perinatal wellbeing and explores relevant elements of well-being. The review's novel approach to the synthesis of theoretical discussions provides a broad foundation for the development of a comprehensive conceptual framework of PWB and the underpinnings for the design of a measure of PWB in the future. The details of the process of synthesis provided in the supplementary material provide a large degree of transparency.

The main limitation of this paper lies in the difficulty of identifying theoretical discussions of PWB in the academic literature. Papers were only included if they explicitly referred to theories, models, conceptualisations or frameworks. Consequently only a small number of papers were included, reflecting the paucity of theorising around perinatal well-being. We addressed this challenge by using extensive scoping searches to identify the most appropriate search strategy and by rigorously applying inclusion and exclusion criteria. A further challenge was that the included papers varied greatly in their nature and content, which made comparisons difficult and called for a more innovative approach to literature synthesis.

\section{Conclusions}

Perinatal well-being is multidimensional: all domains of women's life can influence well-being. The importance of specific domains varies between women and over time. During the perinatal period specific issues are likely to become of particular significance. Perinatal well-being is a dynamic and a subjective, individual experience consisting of physical/embodied, affective and psychological/cognitive elements, which can be both positive and negative. Well-being may depend to a considerable extent on how women cope with challenging situations, drawing on internal skills and external resources. While none of the models/conceptualisations individually addresses all of these points, taken together they provide a good basis for the development of a comprehensive model of perinatal well-being. We have presented a tentative model of perinatal well-being which can be used as the basis for further theoretical discussions and research.

This review illustrates the need for a multi-disciplinary approach to the study of perinatal well-being which is able to address the complex web of interactions between contextual factors, individual differences and changes over time. A measure of perinatal well-being needs to be able to take into account all the elements discussed in this review and provide more than a uni-dimensional assessment. Furthermore, this review highlights the need for woman-centred care which can meet the needs of individual women and considers their circumstances. Finally, as O'Brien et al. (1999) suggest, it is important to recognise that any conceptualisation of perinatal well-being is likely to change over time as we gather more research evidence and refine theoretical thinking. 


\section{References}

Abrams, L. S., Curran, L. 2009. “And You're Telling Me Not to Stress?” a Grounded Theory Study of Postpartum Depression Symptoms among Low-Income Mothers. Psychology of Women Quarterly 33 (3), 351-362. doi:10.1177/036168430903300309

Alderdice, F., McNeill, J., Gargan, P., Perra, O. 2017. Preliminary evaluation of the Well-being in Pregnancy (WiP) questionnaire. Journal Of Psychosomatic Obstetrics And Gynaecology 38 (2), 133-142. doi:10.1080/0167482X.2017.1285898

Alderdice, F., Gargan, P. 2019. Exploring subjective wellbeing after birth: A qualitative deductive descriptive study. European Journal of Midwifery, 3. doi: https://doi.org/10.18332/ejm/104679

Allan, C., Carrick-Sen, D., Martin, C. R. 2013. What is perinatal well-being? A concept analysis and review of the literature. Journal of Reproductive and Infant Psychology 31 (4), 381-398. doi:10.1080/02646838.2013.791920

Ayers, S., Olander, E. K. 2013. What are we measuring and why? Using theory to guide perinatal research and measurement. Journal of Reproductive and Infant Psychology 31 (5), 439-448. doi:10.1080/02646838.2013.834041

Bell, A. F., Andersson, E. 2016. The birth experience and women's postnatal depression: A systematic review. Midwifery 39, 112-123. doi:https://doi.org/10.1016/j.midw.2016.04.014

Bronfenbrenner, U. 2005. Ecological systems theory (1992). In Bronfenbrenner, U. (Ed.) Making human being human: Bioecological perspectives on human development. Sage Publications, Thousand Oaks, CA

Byrne, V., Egan, J., Mac Neela, P., Sarma, K. 2017. What about me? The loss of self through the experience of traumatic childbirth. Midwifery 51, 1-11. doi:https://doi.org/10.1016/j.midw.2017.04.017

CEMACH. 2007. Saving mothers' lives: reviewing maternal deaths to make motherhood safer - 2003-2005. Retrieved from London: www.cmace.org.uk/publications

Choi, P., Henshaw, C., Baker, S., Tree, J. 2005. Supermum, superwife, supereverything: performing femininity in the transition to motherhood. Journal of Reproductive and Infant Psychology 23 (2), 167-180. doi:10.1080/02646830500129487

Clarry, L., Carson, J. 2018. Development and pilot of a positive measure of maternal mental health: The C-MEWS. Journal of Health Visiting 6 (8), 394-403. doi:10.12968/johv.2018.6.8.394

Crowther, S. 2018. Childbirth as a sacred celebration. In: Crowther, S. and Hall, J. (Eds.), Spirituality and Childbrith. Meaning and Care at the Start of Life. Routledge, London.

Crowther, S., Stephen, A., Hall, J. 2019. Association of psychosocial-spiritual experiences around childbirth and subsequent perinatal mental health outcomes: an integrated review. Journal of Reproductive and Infant Psychology. doi: 10.1080/02646838.2019.1616680

Darvill, R., Skirton, H., Farrand, P. 2010. Psychological factors that impact on women's experiences of first-time motherhood: a qualitative study of the transition. Midwifery 26 (3), 357-366. doi:https://doi.org/10.1016/j.midw.2008.07.006

Diener, E. 1984. Subjective well-being. Psychological Bulletin 95, 542-575. doi:10.1037/0033-2909.95.3.542

Diener, E. 1994. Assessing subjective well-being: Progress and opportunities. Social 
Dodge, R., Daly, A. P., Huyton, J., Sanders, L. D. 2012. The challenge of defining wellbeing. International Journal of Wellbeing 2 (3), 222-235.

Downe, S., Finlayson, K., Oladapo, O. T., Bonet, M., Gülmezoglu, A. M. 2018. What matters to women during childbirth: A systematic qualitative review. PLoS One 13 (4), e0194906. doi:10.1371/journal.pone.0194906

Fahey, J. O., Shenassa, E. 2013. Understanding and meeting the needs of women in the postpartum period: The perinatal maternal health promotion model. J Midwifery Womens Health 58 (6), 613-621. doi:10.1111/jmwh.12139

Fahy, K. M., Parratt, J. (2006). Birth Territory: A theory for midwifery practice. Women and Birth 19 (2), 45-50. doi:https://doi.org/10.1016/j.wombi.2006.05.001

Galatzer-Levy, I. R., Mazursky, H., Mancini, A. D., Bonanno, G. A. 2011. What we don't expect when expecting: evidence for heterogeneity in subjective well-being in response to parenthood. J Fam Psychol 25 (3), 384-392. doi:10.1037/a0023759

Greco, G., Skordis-Worrall, J., Mkandawire, B., Mills, A. 2015. What is a good life? Selecting capabilities to assess women's quality of life in rural Malawi. Social Science \& Medicine 130, 69-78. doi:10.1016/j.socscimed.2015.01.042

Hauck, Y., Fenwick, J., Downie, J., Butt, J. 2007. The influence of childbirth expectations on Western Australian women's perceptions of their birth experience. Midwifery 23 (3), 235-247. doi:https://doi.org/10.1016/j.midw.2006.02.002

Hodgkinson, E. L., Smith, D. M., Wittkowski, A. 2014. Women's experiences of their pregnancy and postpartum body image: a systematic review and meta-synthesis. BMC Pregnancy and Childbirth 14 (1), 330. doi:10.1186/1471-2393-14-330

Jomeen, J., Martin, C. 2018. Well-being and quality of life in a maternal health context. In: Galvin, K. (Ed.), Routledge Handbook of Well-Being. Routledge, Abingdon.

Keyes, C.L.M. 1998. Social well-being. Social Psychology Quarterly 61 (2), 121-140. doi: $10.2307 / 2787065$

Kirova, K., Snell, T. 2019. Women's experiences of positive postnatal partner support. Journal of Reproductive and Infant Psychology 37 (2), 206-218. doi: 10.1080/02646838.2018.1542120

Knight, M., Bunch, K., Tuffnell, D., Jayakody, H., Shakespeare, J., Kotnis, R., Lemupm. S., Kurinczuk, J. J. (Eds.) 2018. Saving Lives, Improving Mothers' Care - Lessons learned to inform maternity care from the UK and Ireland Confidential Enquiries into Maternal Deaths and Morbidity 2014-16. Retrieved from https://www.npeu.ox.ac.uk/downloads/files/mbrrace-uk/reports/MBRRACEUK\%20Maternal\%20Report\%202018\%20-\%20Web\%20Version.pdf

Kristensen, I. H., Simonsen, M., Trillingsgaard, T., Pontoppidan, M., Kronborg, H. 2018. Firsttime mothers' confidence mood and stress in the first months postpartum. A cohort study. Sexual \& Reproductive Healthcare 17, 43-49. doi:https://doi.org/10.1016/j.srhc.2018.06.003

Larkin, P., Begley, C. M., Devane, D. 2009. Women's experiences of labour and birth: an evolutionary concept analysis. Midwifery 25 (2), e49-e59. doi:https://doi.org/10.1016/j.midw.2007.07.010

Law, K. H., Dimmock, J., Guelfi, K. J., Nguyen, T., Gucciardi, D., Jackson, B. 2018. Stress, Depressive Symptoms, and Maternal Self-Efficacy in First-Time Mothers: Modelling and Predicting Change across the First Six Months of Motherhood. Applied Psychology: Health and Well-Being 11 (1), 126-147. doi:doi:10.1111/aphw.12147 
Lundgren, I. 2005. Swedish women's experience of childbirth 2 years after birth. Midwifery 21 (4), 346-354. doi:https://doi.org/10.1016/j.midw.2005.01.001

McKenzie-McHarg, K., Ayers, S., Ford, E., Horsch, A., Jomeen, J., Sawyer, A., Stramrood, C., Thomson, G., Slade, P. 2015. Post-traumatic stress disorder following childbirth: an update of current issues and recommendations for future research. Journal of Reproductive and Infant Psychology 33 (3), 219-237. doi:10.1080/02646838.2015.1031646

McLeish, J., Redshaw, M. 2017. Mothers' accounts of the impact on emotional wellbeing of organised peer support in pregnancy and early parenthood: a qualitative study. BMC Pregnancy and Childbirth 17(1). doi: 10.1186/s12884-017-1220-0

Milgrom, J., Gemmill, A. W., Bilszta, J. L., Hayes, B., Barnett, B., Brooks, J., Ericksen, J., Ellwood, D., Buist, A. 2008. Antenatal risk factors for postnatal depression: A large prospective study. Journal of Affective Disorders 108 (1), 147-157. doi:https://doi.org/10.1016/j.jad.2007.10.014

Moher, D., Liberati, A., Tetzlaff, J., \& Altman, D. G. (2009). Preferred reporting items for systematic reviews and meta-analyses: the PRISMA Statement. British Medical Journal, 339(b2535).

Neiterman, E., Fox, B. 2017. Controlling the unruly maternal body: Losing and gaining control over the body during pregnancy and the postpartum period. Social Science \& Medicine 174, 142-148. doi:https://doi.org/10.1016/j.socscimed.2016.12.029

Newham, J. J., Martin, C. R. 2013. Measuring fluctuations in maternal well-being and mood across pregnancy. Journal of Reproductive and Infant Psychology 31 (5), 531-540. doi:10.1080/02646838.2013.834040

Nilsson, C., Hessman, E., Sjöblom, H., Dencker, A., Jangsten, E., Mollberg, M., Patel, H., Sparud-Lundin, C., Wigert, H., Begley, C. 2018. Definitions, measurements and prevalence of fear of childbirth: a systematic review. BMC Pregnancy and Childbirth 18, 28. doi:10.1186/s12884-018-1659-7

O'Brien, B., Evans, M., Medves, J. 1999. Perinatal comfort and well-being as a developmental concept. Western Journal Of Nursing Research 21 (3), 288-291.

Oates, M. R., Cox, J. L., Neema, S., Asten, P., Glangeaud-Freudenthal, N., Figueiredo, B., Gorman, L. L., Hacking, S., Hirst, E., Kammerer, M. H., Klier, C. M., Seneviratne, G., Smith, M., Sutter-Dallay, A.-L., Valoriani, V., Wickberg, B., Yoshida, K. 2018. Postnatal depression across countries and cultures: a qualitative study. British Journal of Psychiatry 184 (S46), s10-s16. doi:10.1192/bjp.184.46.s10

Parratt, J. 2010. 'Feeling like a genius: enhancing women's changing embodied self during first childbearing'. (PhD), University of Newcastle, Newcastle, NSW, Australa. Retrieved from https://epubs.scu.edu.au/hahs_pubs/1578/

Pies, C., Parthasarathy, P, Posner, S.F. 2012. Integrating the life course perspective into a local Maternal and Child Health Program. Maternal and Child Health Journal 16 (3), 649-655. doi:10.1007/s10995-011-0800-2

Posmontier, B., Horowitz, J. A. 2004. Postpartum Practices and Depression Prevalences: Technocentric and Ethnokinship Cultural Perspectives. Journal of Transcultural Nursing 15 (1), 34-43. doi:10.1177/1043659603260032

Reis, P. J., Alligood, M. R. 2008. Well-being in pregnancy: a pilot study using the Well-being Picture Scale. Visions: The Journal of Rogerian Nursing Science 15 (1), 8-17. 
Reis, P. J., Alligood, M. R. 2014. Prenatal Yoga in Late Pregnancy and Optimism, Power, and Well-Being. Nursing Science Quarterly 27 (1), 30-36. doi:10.1177/0894318413509706

Russell, B. S., Lincoln, C. R. 2016. Distress Tolerance and Emotion Regulation: Promoting Maternal Well-Being Across the Transition to Parenthood. Parenting 16 (1), 22-35. doi:10.1080/15295192.2016.1116893

Ryff, C. D. 1989. Happiness is everything, or is it? Explorations on the meaning of psychological well-being. Journal of Personality and Social Psychology 57, 1069-1081. doi:10.1037/0022-3514.57.6.1069

Ryff, C. D., Keyes, C. L. 1995. The structure of psychological well-being revisited. Journal of Personality and Social Psychology 69 (4), 719-727.

Sampson, M., Torres, M. I. M., Duron, J., Davidson, M. 2018. Latina Immigrants' Cultural Beliefs About Postpartum Depression. Affilia 33 (2), 208-220. doi:10.1177/0886109917738745

Schaffir, J., Kunkler, A., Lynch, C. D., Benedict, J., Soma, L., Doering, A. 2018. Association between postpartum physical symptoms and mood. Journal of Psychosomatic Research 107, 33-37. doi:https://doi.org/10.1016/j.jpsychores.2018.02.003

Segre, L. S., O'Hara, M. W., Arndt, S., Stuart, S. 2007. The prevalence of postpartum depression. Social Psychiatry and Psychiatric Epidemiology 42 (4), 316-321. doi:10.1007/s00127-007-0168-1

Seligman, M. 2011. Flourish: A new understanding of happiness, well-being - and how to achieve them. Free Press, London.

Sen, A. 1993. Capability and well-being. In Nussbaum, M., Sen, A. (Eds.), The Quality of Life (pp. 30-54). Clarendon Press, Oxford.

Simkin, P. 1991. Just Another Day in a Woman's Life? Women's Long-Term Perceptions of Their First Birth Experience. Part I. Birth 18 (4), 203-210. doi:doi:10.1111/j.1523536X.1991.tb00103.x

Smart, J., Hiscock, H. 2007. Early infant crying and sleeping problems: A pilot study of impact on parental well-being and parent-endorsed strategies for management. Journal of Paediatrics and Child Health 43 (4), 284-290. doi:doi:10.1111/j.14401754.2007.01060.x

Symon, A., MacDonald, A., Ruta, D. 2002. Postnatal Quality of Life Assessment: Introducing the Mother-Generated Index. Birth 29 (1), 40-46. doi:doi:10.1046/j.1523536X.2002.00154.x

Tammentie, T., Paavilainen, E., Åstedt-Kurki, P., Tarkka, M.-T. 2004. Family dynamics of postnatally depressed mothers - discrepancy between expectations and reality. Journal of Clinical Nursing 13 (1), 65-74. doi:doi:10.1046/j.1365-2702.2003.00824.x

Thomas, J., Harden, A. 2008. Methods for the thematic synthesis of qualitative research in systematic reviews. BMC Medical Research Methodology 8 (1), 45. doi:10.1186/1471-2288-8-45

Verreault, N., Da Costa, D., Marchand, A., Ireland, K., Dritsa, M., Khalifé, S. 2014. Rates and risk factors associated with depressive symptoms during pregnancy and with postpartum onset. Journal of Psychosomatic Obstetrics \& Gynecology 35 (3), 84-91. doi:10.3109/0167482X.2014.947953

Wall, G. 2013. 'Putting family first': Shifting discourses of motherhood and childhood in representations of mothers' employment and child care. Women's Studies International Forum 40, 162-171. doi:https://doi.org/10.1016/j.wsif.2013.07.006 
